\title{
Movie Narrative: A Study on the Narrative Beat of Movie Scenes
}

\author{
Jiatong Han \\ Department of Screenwriting, Beijing Film Academy, Beijing 100088, China \\ Email: hanjiatong87@163.com
}

\begin{abstract}
The beat is a kind of behavioral communication in the action or reaction. The dramatic action and the reaction with dramatic conflict together construct a narrative beat, and the dramatic conflict is the basis for establishing the narrative beat. The narrative of movie scenes should revolve around the same drama task. The establishment of narrative beats within the scene makes the drama conflict of events progressive and escalating. The narrative beat is a strategy to grasp the narrative rhythm, a method to create suspense, and a way to lay out the structure of the story.
\end{abstract}

Keywords: narrative beat, drama conflict, movie scene, suspense

\section{Introduction}

How to make the narrative rhythm of the movie scene distinct? A Japanese "Noh" drama master created the famous JO-HAI-KIU rule. He believes that not only must the whole play be divided into three parts of the movement, but also every scene, every paragraph, and sometimes even all the lines of the play must be divided into three parts. These three basic beats are used repeatedly at each stage, but they cannot be perfectly translated into any language (we can translate into: preparation, development, climax). For those who feel clueless about writing and don't know where to start, they still have something to learn from. ${ }^{[1]}$

In Robert McKee's book Story: Substance, Structure, Style, and the Principles of Screenwriting, the definition of "beat" is proposed. He believes that "beat is a kind of behavior communication in action/reaction. These changing behaviors construct the transformation of the scene through one beat after another." [2] "According to Robert McKee's vision, a complete movie story The body is made up of several components. The smallest unit is the 'beat', which is basically just a moment of action and behavior between characters." ${ }^{[3]}$ Dramatic action and the reaction with dramatic conflict together construct a narrative beat, and drama conflict is the basis for constructing narrative rhythm.

\section{Dramatic action and drama conflict constitute the narrative beat}

The dramatic action will usher in the reactions of the surrounding world. The reaction should not conform to the dramatic action, but should have a dramatic conflict with the dramatic action. "Conflict does not have to be violent. Each action prompts the other party to react and confront, rather than seek a 'solution'. The conflict continues to escalate, forcing the characters to collide with each other and pushing the plot forward." ${ }^{[4]}$ Regardless of whether the party issuing the dramatic action is the subject or the stereo, and whether the responding party is the subject or the stereo, the antagonistic relationship between the dramatic action and the drama conflict can be regarded as a "round". If this "round" is regarded as a contest between the enemy and ourselves, then this round can be called a "beat" again. It is like the subject is the left hand and the right hand for the stereo. The conflict between the left hand and the right hand once is a "beat."

Narrative beat is a narrative strategy. It is a collision between character action and conflict. It is built on the basis of drama conflict and used to divide the level of events. It continues the audience's attention to the characters and events, and continues the suspense.

For example, in the movie Notting Hill, the incident in which Anna came to the bookstore to confess to Seck can be divided into the following four narrative beats, and each narrative beat is built around drama tasks and drama conflicts.

Narrative beat (1): Anna comes in and wants to chat with Seke in the name of sending a picture, but is interrupted by a customer. The customer's interruption is a dramatic conflict of the narrative beat.

Narrative beat (2) : After the customer left, Anna finally plucked up the courage to confess to Seke, hoping to get Seke's response. As a result, Seke's colleague said that Seke's mother called and hoped that Seke would listen to the phone immediately. Then, this call from Seck's mother is a dramatic conflict of narrative beats.

Narrative beat (3): Seke enters the office to listen to the phone, Anna has to wait for Seke, and has a non-speculative small chat with Seke's colleagues. Anna is anxious awaiting Seck's final verdict on this love. Colleagues' conversations, waiting time, and inner suffering are all the dramatic conflicts of this narrative beat. 
Narrative beat (4): Seck came out and rejected Anna. Anna tried her best to persuade Seck, but eventually ended in failure and had to leave. In this narrative beat, Seck's refusal is a dramatic conflict confessed by Anna.

The dramatic action of the characters in order to complete the dramatic task and the dramatic conflict generated by the reaction of the surrounding world construct a narrative beat. The establishment of the narrative beat makes the characters difficult to achieve the theatrical task, with twists and turns.

The scene serves the narrative of the event. One scene can complete the narrative of an event, and multiple scenes can also complete the narrative of an event. The establishment of narrative rhythm can enable the playwright to grasp the narrative rhythm of the event more clearly; make the narrative structure of the events within the scene more hierarchical; enable the drama conflict to be narrated progressively; make the audience's achievement of the characters' dramatic tasks and Whether it is more expectant, which increases the suspense of the narrative.

If the scenes and events lack the establishment of dramatic conflicts and the narrative rhythm, the progress of the event will stand still and cannot be advanced, and thus there will be no twists and turns, and the suspense will be lost. It is precisely because the characters have experienced dramatic conflicts and different narrative rhythms between raising and solving problems, that makes the story twists and turns and makes people feel the joy of watching the movie.

\section{The narrative mode of one event and one scene}

The narrative of the event can be completed within a single scene. The whole scene revolves around the characters' dramatic tasks, and multiple narrative beats can be built according to the conflict of the drama. For example, in the movie Moonstruck, Lolita's family waited for Johnny to arrive together. The drama task is for Lolita to confess the truth of empathy to Johnny, and drama conflict is the danger brought by Johnny's arrival.

Narrative beat (1) Scene: Lolita's dining room

Lolita confessed to her mother that she was in love with Johnny's younger brother Ronnie, and she wanted to wait for Johnny to come to show her thoughts. The first doorbell rang, and Ronnie's arrival interrupted the mother and daughter's conversation, increasing the sense of crisis in the dramatic conflict. Audiences are beginning to worry about what will happen to this relationship once the love triangle is announced.

Narrative beat (2) Scene: Lolita's dining room

After Ronnie arrived, he had breakfast with Lolita's family. Everyone began to worry about the arrival of Johnny, for fear that Johnny witnessed the fact that Lolita and Ronnie were together and caused a war. As a result, the second doorbell rang, and everyone was falsely alarmed and discovered that Lolita's uncle and aunt were visiting.

Narrative beat (3) Scene: Lolita's dining room

Lolita's uncle and aunt came to get back their previous savings and joined the family's breakfast, waiting for Johnny's arrival and the outbreak of the crisis together. Until the third doorbell rang, Johnny really came.

Narrative beat (4) Scene: Lolita's dining room

After Johnny arrived, before Lolita could confess the truth about the transference, he encountered Johnny's repentant marriage. Lolita threw the engagement ring to Johnny in anger. At this time, Ronnie used the same ring to propose to Lolita, making Johnny shocked. In the end, Lolita and Ronnie got true love under the blessing of everyone.

The play of Moonstruck follows the "classical unities" writing method of drama. At a specific time, at a specific place, through a specific relationship between characters, the drama conflict is displayed. Within a single scene, the tempo is built around drama tasks and drama conflicts. One is to promote the continuous escalation of drama conflicts, and the other is to show the changes in drama conflicts through character relationships.

The dramatic task of this event is for Lolita to confess the truth of the empathy to Johnny. The playwright did not write that Johnny entered the door immediately and the conflict could break out. Instead, the three doorbells rang through the entrance of Ronnie, his uncle and aunt and Johnny, which triggered three escalations of drama conflicts. This makes the drama conflict of the whole event progressive, the sense of crisis is escalating, the rhythm is more distinct, the structure is more layered, and the suspense is stronger. At the same time, the three entrances of different characters changed the relationship between the characters in the scene and made the narrative more layered.

\section{A narrative mode of multiple scenes in one event}

The narrative of the event can be completed in a single scene or in multiple scenes. Take the confession incident of Seck in the movie Notting Hill as an example. The task of the drama is for Seck to confess to Anna. On this basis, four drama conflicts were built, divided into the following four narrative beats.

Narrative beat (1) Scene: street 
Seke decided to find Anna, and drove to the hotel where Anna was staying with his friends. This dramatic conflict of narrative beats is time urgency. Once the two miss meeting, Anna will leave the UK.

Narrative beat (2) Scene: hotel front desk

Seke and friends came to the hotel to ask the front desk staff about Anna's whereabouts, and learned that Anna had left the hotel and was holding a press conference. This dramatic conflict of narrative beats was missed by the two, and Seck needs to find Anna immediately.

Narrative beat (3) Scene: street

Seke and his friend encountered a traffic jam on their way to the press conference site. Under the command of his friend Spike, Seke finally came to the hotel where the press conference was held. The dramatic conflict of the drama beat is the traffic jam on the street, which hinders the achievement of Seck's drama mission.

Narrative beat (4) Scene: hotel

Seck and his friends came to the hotel where the press conference was held, and they finally confessed to Anna. The dramatic conflict in the beat of this drama is whether Seke has the courage to defeat himself and confess his courage.

When an event is narrated by multiple scenes, the scene should serve the narrative beat. In some cases, one scene completes a narrative beat narrative, and in other cases, multiple scenes complete a narrative beat narrative.

\section{Narrative mode of compound events}

In addition to telling a single event, event narration can also tell two or more events at the same time. This way of narrative is called "montage narrative". In many scripts, playwrights are using "editing writing" ${ }^{[1]}$. This is an activity that only exists in movies and is unique in the history of language expression. It is "Montage Narrative". The film writer should have the mentality of montage narrative. When the script takes shape, regardless of whether the shots have been divided, in the text itself, the knowledge of montage is the same as the knowledge of light and sound. "Montage narrative" can stimulate the imagination, can find a way that cannot be expressed in words, through a close-up shot, a glance, and a detail to make a scene lively, and make an action neurotic and rigid. ${ }^{[1]}$ The playwright should apply montage thinking to the narrative of the event, reorganize and arrange the plot information, and complete the narrative of the compound event.

In A Beautiful Mind, the incident of Nash working for the National Security Agency and the incident of Nash and Alicia falling in love are narrated at the same time. If the event working for the National Security Agency is the event a and the event where Nash and Alicia fall in love is the event b, then these two events have their own narrative tempo.

The narrative beat of the event a (the event where Nash worked for the National Security Agency)

a1 Narrative beat (1) Scene: National Security Agency

Nash entered the National Security Agency to decipher the military code for the country.

a2 Narrative beat (2) Scene: outside the office, street, secret military base

Nash met a mysterious man and was hired to crack the code for the country.

a3 narrative beat (3) Scene: outside the office, the mysterious villa

Nash sends a letter to the military base.

a4 Narrative beat (4) Scene: inside the car, outside the car, street

Nash was attacked.

The narrative beat of the event $b$ (the event in which Nash and Alicia fall in love)

b1 Narrative beat (1) Scene: school office, classroom

Nash met Alicia in class.

b2 Narrative beat (2) Scene: office, inside the cocktail party, outside the cocktail party

Nash takes Alicia to the reception, and the two have a good feeling for each other.

b3 Narrative beat (3) Scene: park, campus, restaurant, church

Nash proposes to Alicia and the two get married.

b4 Narrative Beat (4) Scene: home

Nash found danger and told Alicia to leave him.

The narration of the two events in A Beautiful Mind does not follow a single event sequentially, but uses parallel montages to complete the narration of the two events. The order of narration is: $a 1+b 1+a 2+b 2+a 3+b 3+a 4+b 4$. It can be seen that, for the narrative of compound events, it is also necessary to divide the narrative beats within each event, and then perform parallel narratives in accordance with the montage narrative method. The narrative still has to follow the structural rules of initiation, inheritance, transformation and integration.

Of course, in the narrative of certain complex events, sometimes the narrative beats of all events may not be 
displayed, but the narrative events of a certain event are the main narrative events, and the narrative beats of other narrative events are selectively explained. For example, in 3 Idiots, the incident of Rancho's research on the aircraft and the suicide of his senior fellow apprentice are also narrated simultaneously. However, it focuses on the incident of Rancho's research on the aircraft, and selectively narrates the internal narrative beat of the suicide incident of his senior fellow apprentice.

The narrative rhythm of the event a (study aircraft event)

Narrative beat (1) Scene: dormitory corridor, inside the dormitory

Rancho found that his brother had lost the aircraft, so he decided to help him prepare the aircraft, and discussed with his friends Farhan and Raja in the dormitory about how to study the aircraft.

Narrative beat (2) Scene: bathroom, classroom, campus, roof, dormitory

Show Rancho's thinking in the process of research through singing and dancing.

Narrative beat (3) Scene: bathroom, classroom, campus, roof, dormitory

It was demonstrated through singing and dancing that Rancho thought of a solution in his research.

Narrative Beat (4) Scene: downstairs of the dormitory

Rancho let the aircraft fly.

The narrative beat of the event $b$ (the suicide of his senior fellow apprentice)

Narrative beat (1) Scene: dormitory corridor

Faced with not being able to graduate, the senior fellow apprentice played the guitar and sang, depressed.

Narrative beat (2) Hypothetical

The senior fellow apprentice faces pressure from family and school.

Narrative beat (3) Hypothetical

The senior fellow apprentice decided to commit suicide.

Narrative beat (4) Scene: inside the dormitory

The senior fellow apprentice hanged himself in the dormitory.

The narrative of the two incidents in 3 Idiots uses parallel montages to complete the narrative of the two incidents. The narrative sequence is: $\mathrm{a} 1+\mathrm{b} 1+\mathrm{a} 2+\mathrm{a} 3+\mathrm{a} 4+\mathrm{b} 4$, and the two narrative beats of the $\mathrm{b}$ event are hidden in the narrative. Although the narrative did not show how the brother faced the pressure of his family and study, and how he chose to commit suicide, the audience was still able to speculate on the course of the event through the narrative beat (1) and narrative beat (4) of the event $b$.

In order to complete the narrative of compound events, the narrative beat of each event must be divided first according to the structural rules of initiation, inheritance, transfer, and union, and then through montage narrative, parallel montage is used to simultaneously narrate two or more events. When necessary, part of the narrative beat of certain events can be hidden without affecting the completion of the narrative.

\section{Conclusion}

The scene serves the narrative of the event. One scene can complete the narrative of an event, or multiple scenes can complete the narrative of an event. The narrative of the movie scene should revolve around the same drama task. The establishment of the narrative beat within the scene makes the drama conflict of the event progressive and escalating.

The research on narrative rhythm is based on the research of predecessor scholars, with the theory of drama conflict. Through the analysis of classic genre events in genre movies, it explores and studies the commonality of creating suspense through narrative beats, and summarizes and summarizes the rules of genre events in movies. Playwrights use the establishment of narrative beats to act on the presentation of art and enhance the aesthetic mood of the work. The narrative beat is a strategy to grasp the narrative rhythm, a method to create suspense, and a way to lay out the structure of the story.

\section{References}

[1] Jean-Claude Carrière, Pascal Bonitzer. Translated by Mei Feng, Liu Jie. Exercises of Scenarios. Beijing: China Film Publishing House; 2001.

[2] Robert McKee. Translated by Zhou Tiedong. Story: Substance, Structure, Style, and the Principles of Screenwriting. Beijing: China Film Publishing House; 2001.

[3] Dan O'Bannon. Collated by Matt R. Lohr. Translated by Gao Yuan. Guide to Screenplay Structure. Beijing: Beijing United Publishing Company; 2015.

[4] Xu Daojun. Story Workshop. Beijing: Renmin University of China Press; 2015. 